\title{
Desempenho e metabolismo ruminal em bovinos de corte em sistema de pastejo no periodo seco do ano recebendo virginiamicina na dieta
}

\author{
Performance and ruminal metabolism in beef cattle in grazing \\ system in the dry period of year receiving virginiamycin in the diet
}

\author{
Sérgio Fernandes Ferreira ${ }^{1 *}$; Juliano José de Resende Fernandes ${ }^{2}$; \\ João Teodoro Pádua²; Ubirajara Oliveira Bilego ${ }^{3}$; Marcos Antônio Sales Lima ${ }^{3}$; \\ Aldi Fernandes de Souza França ${ }^{2}$; Elis Aparecido Bento ${ }^{4}$; \\ Leonardo Guimarães Oliveira; ${ }^{5}$ Danilo Grandini ${ }^{6}$
}

\begin{abstract}
Resumo
Objetivou-se avaliar os efeitos da inclusão de virginiamicina (VM) em dois níveis, ao suplemento proteico-energético para bovinos de corte em crescimento com dieta a base de gramínea tropical no período seco do ano. Foram constituídos três tratamentos: tratamento controle, apenas Suplemento Mineral COMIGO - Produção - F.10 proteico-energético (SPE); tratamento virginiamicina 100 (VM 100), SPE + $108 \mathrm{mg}$ de (Phigrow $\left.{ }^{\circledR}\right) \mathrm{VM} /$ animal/dia e tratamento virginiamicina 200 (VM 200), SPE + $216 \mathrm{mg}$ de (Phigrow $\left.{ }^{\circledR}\right) \mathrm{VM} /$ animal/dia. As variáveis analisadas foram o consumo de suplemento (CSPE), ganho médio diário (GMD), medidas biométricas e escore de condição corporal (ECC) no experimento 1 e o consumo médio diário de suplemento (CSM), pH ruminal, nitrogênio amoniacal, degradabilidade ruminal in situ da matéria seca (MS), da fibra em detergente acido (FDN) e da fibra em detergente neutro (FDA) no experimento 2. Não houve diferença estatística para GMD, CSPE e para medidas biométricas ( $\mathrm{P}>0,05)$, GMD para VM 200 de 0,431; VM 100 de 0,391 e controle de 0,398 kg/ animal/dia. Não houve diferença significativa $(\mathrm{P}>0,05)$ do $\mathrm{pH}$ ruminal, da concentração de nitrogênio amoniacal e das variáveis analisadas na degradabilidade ruminal in situ da MS, da FDN e da FDA. A virginiamicina veiculada no SPE para bovinos de corte sob pastejo pode promover a variação de consumo, não promoveu efeitos significativos nos valores do $\mathrm{pH}$ ruminal e do nitrogênio amoniacal e não demonstram efeitos significativos sobre a degradabilidade da MS, FDN e FDA.

Palavras-chave: Aditivos zootécnicos, degradação da fibra, suplementação proteico-energética
\end{abstract}

\footnotetext{
Abstract

This study aimed to evaluate the effects of including virginiamycin (VM) in two levels, the proteinenergy supplement for growing beef cattle diet with the tropical grass base in the dry season. Three treatments were evaluated: control treatment, only Mineral Supplement ME - Production - F.10 proteinenergy (SPE); 100 virginiamycin treatment (VM 100) + SPE $108 \mathrm{mg}\left(\right.$ Phigrow $\left.{ }^{\circledR}\right) \mathrm{VM} /$ animal / day

${ }^{1}$ Prof., Instituto Federal Catarinense, Campus Concórdia, IFC, Concórdia, Concórdia, SC. E-mail: sergio-ff@hotmail.com

2 Profs., Universidade Federal de Goiás, UFG, Goiânia, GO. E-mail: juliano@vet.ufg.br; joao.teodoro@pq.cnpq.br; aldi@vet.ufg.br

${ }^{3}$ Pesquisadores, Cooperativa Agroindustrial dos Produtores Rurais do Sudoeste Goiano, COMIGO, Rio Verde, GO. E-mail: birabilego@yahoo.com.br; marcosifgoianorv@yahoo.com.br

${ }^{4}$ Prof., Instituto Federal Goiano, Campus Rio Verde, IFGoiano, Rio Verde, GO. E-mail: elisbentorv@gmail.com

5 Pesquisador, UFG, Goiânia, GO. E-mail: leonardogovet@hotmail.com

${ }^{6}$ Pesquisador, Phibro Animal Health Corporation, PHIBRO, Campinas, SP. E-mail: danilo.grandini@pahc.com
}

* Autor para correspondência 
and treatment virginiamycin $200\left(200\right.$ MV) + SPE $216 \mathrm{mg}\left(\right.$ Phigrow $\left.{ }^{\circledR}\right) \mathrm{VM} /$ animal / day. The variables analyzed were the supplement intake (SI), average daily gain (ADG), biometric measurements and body condition score (BCS) in experiment 1 and the average daily supplement intake (ADSI), ruminal $\mathrm{pH}$, ammonia nitrogen, in situ ruminal degradability of dry matter (DM), acid detergent fiber (ADF) and neutral detergent fiber (NDF) in experiment 2. There was no statistical difference for ADG, SI and biometric measurements ( $\mathrm{P}>0.05)$, ADG for VM 200 of 0,431 ; VM 100 of 0.391 and control $0.398 \mathrm{~kg}$ / animal/day. There was no significant difference $(\mathrm{P}>0.05)$ for ruminal $\mathrm{pH}$, the ammonia concentration and the variables at the in situ degradability of DM, NDF and ADF. The virginiamycin conveyed in SPE for beef cattle grazing can promote changes in consumption did not cause significant effects on the values of ruminal $\mathrm{pH}$ and ammonia nitrogen and do not show significant effects on the degradability of DM, NDF and ADF.

Key words: Zootechnical additives, fiber degradation, protein-energy supplementation

\section{Introdução}

A alimentação é um dos principais componentes do sistema de produção, que é o componente mais importante dentre os fatores ambientais que influenciam o desempenho dos animais (MALAFAIA et al., 2003). No intuito de promover um alto e eficiente desempenho produtivo na criação de bovinos de corte, deve-se levar em consideração a interação entre os animais e seu ambiente criatório. Com isso, grandes avanços em pesquisas científicas vem ocorrendo na área de nutrição animal, em especial quanto ao estudo dos processos fisiológicos e como diferentes fatores os afetam. Em especial os aditivos que são usados como melhoradores do desempenho animal.

A virginiamicina é uma combinação antibiótico polipeptídico cíclico, produto da fermentação de varias espécies de Streptomyces $s p$., sendo a principal delas a Streptomyces virginiae, constituído por dois componentes principais, o virginiamicina fator $\mathrm{M} 1 \mathrm{e}$ o virginiamicina fator S1, que são sinérgicos e tem atividade microbiana. Este antibiótico não ionóforo atua por meio de ligação com os ribossomos, inibindo a síntese de proteína de alguns microrganismos (ROGERS et al., 1995).

Tendo em vista as considerações precedentes, foi conduzida a presente experimentação, com o propósito de incluir em dois níveis, aditivo manipulador da microbiota ruminal, virginiamicina, no suplemento proteico-energético para bovinos de corte em crescimento com dieta base de gramínea tropical no período seco, avaliando os efeitos sobre o ganho de peso, medidas biométricas e consumo de suplemento, ainda, avaliar o consumo de suplemento, o pH ruminal, a concentração de nitrogênio amoniacal e a degradabilidade da matéria seca e das fibras em detergente neutro e ácido utilizando técnicas in situ.

\section{Material e Métodos}

Para realização da presente experimentação, houve a submissão do projeto de pesquisa ao Comitê de Ética em Pesquisa da Universidade Federal de Goiás (CoEP-UFG), o qual foi aprovado e está protocolado sob número CoEP-UFG 039/11. Os métodos e procedimentos utilizados neste trabalho foram realizados de acordo com as normas do Colégio Brasileiro de Experimentação Animal (COBEA).

Foram constituídos três tratamentos: tratamento controle, apenas Suplemento Mineral COMIGO - Produção - F.10 proteico-energético (SPE); tratamento virginiamicina 100 (VM 100), SPE + $108 \mathrm{mg}$ de (PhiGrow $\left.{ }^{\circledR}\right) \mathrm{VM} /$ animal/dia e tratamento virginiamicina 200 (VM 200), SM + $216 \mathrm{mg}$ de (PhiGrow ${ }^{\circledR}$ ) VM/animal/dia (Tabela 1).

\section{Experimento 1}

A pesquisa foi conduzida na área experimental de Pecuária do Centro Tecnológico COMIGO 
(CTC). Foram utilizados 45 novilhos inteiros da raça Nelore com peso vivo inicial de $294,3 \mathrm{~kg}(\mathrm{CV}$ $17,97 \%)$, idade de 18,5 meses $( \pm 1,5)$ e escore de condição corporal 4,8 (CV 8,5\%), de mesmo grupo contemporâneo. Os animais foram manejados no período seco do ano em sistema de lotação rotacionada em piquetes de Tifton 85 (Cynodon spp.) que apresentou $60,4 \%$ de $\mathrm{MS}, 6,99 \%$ de
PB e 55,5\% de NDT estimado (SILVA, 1990) e disponibilidade de forragem acima de 2 ton MS.ha-1 no extrato de pastejo, com acesso ao pasto das $14 \mathrm{~h} 00$ às $10 \mathrm{~h} 00$ do dia seguinte e água ad libitum. A suplementação ocorreu em baias separadas para cada tratamento, onde os animais ficavam fechados das $10 \mathrm{~h} 00$ às $14 \mathrm{~h} 00$ para consumo com acesso ad libitum à água.

Tabela 1. Descrição do aditivo utilizado nos tratamentos VM 100 e VM 200 e sua respectiva concentração no suplemento proteico-energético.

\begin{tabular}{lcc}
\hline \multirow{2}{*}{ Nome Comercial } & VM 100 & VM 200 \\
\cline { 2 - 3 } & PhiGrow ${ }^{\circledR}$ & PhiGrow \\
\hline Nome do princípio ativo & virginiamicina & virginiamicina \\
Concentração princípio ativo & $10 \%$ & $10 \%$ \\
Forma & Feed Premix & Feed Premix \\
Concentração do produto no SPE & $3,6 \mathrm{~g} / \mathrm{kg}$ & $7,2 \mathrm{~g} / \mathrm{kg}$ \\
Concentração do princípio ativo no SPE & $360 \mathrm{mg} / \mathrm{kg}$ & $720 \mathrm{mg} / \mathrm{kg}$ \\
Consumo estimado de SPE & $300 \mathrm{~g} / \mathrm{animal} / \mathrm{dia}$ & $300 \mathrm{~g} / \mathrm{animal} / \mathrm{dia}$ \\
Consumo estimado do princípio ativo & $108 \mathrm{mg} / \mathrm{animal} / \mathrm{dia}$ & $216 \mathrm{mg} / \mathrm{animal} / \mathrm{dia}$ \\
\hline
\end{tabular}

SPE - Suplemento Mineral COMIGO Proteico-Energético, Produção - F10.

Fonte: Elaboração dos autores.

Os animais foram distribuídos aleatoriamente em delineamento inteiramente casualizado, para avaliação de desempenho, os tratamentos foram dispostos em três grupos com 15 repetições (animais) cada, cujo modelo matemático é: $y_{i j}=m$ $+t_{i}+b_{j}+e_{i j}$; onde: $y_{i j}$ equivale ao valor observado na $j$-ésima unidade experimental, que recebeu o $i$-ésimo tratamento; $m$ significa a média geral; $t_{i}$ equivale ao efeito $i$-ésimo tratamento; $b_{j}$ equivale ao efeito do $j$-ésimo bloco; $e_{i j}$ é o erro experimental associado a observação $y_{i j^{\prime}}$ Os dados coletados foram analisados estatisticamente com auxilio do programa Statistical Analysis System (SAS, 2000), com médias comparadas pelo teste de Tukey $(\mathrm{P}>0,05)$.

Foram avaliados o consumo médio diário de suplemento (CSM em (g/animal/dia), estimado através da diferença entre a quantidade fornecida e as sobras no cocho; o ganho médio diário (GMD em $\mathrm{kg} / \mathrm{animal} / \mathrm{dia}$ ) por meio de pesagens individuais após imposição de jejum de sólidos de 15 horas; as medidas biométricas de altura de anterior (altura de cernelha), altura de posterior (altura de anca), comprimento corporal, perímetro torácico, largura da garupa, largura do peito (adaptado de FRENEAU et al., 2008) realizadas com uso de fita métrica e bengala hipométrica. E avaliação do escore de condição corporal (ECC), na escala de 1 a 9, onde 1 = animal extremamente magro e $9=$ animal obeso (SPITZER, 1986).

\section{Experimento 2}

A pesquisa foi conduzida na área experimental de Bovinos de Corte do Departamento de Produção Animal - EVZ/ UFG. Foram utilizados seis novilhos castrados da raça Nelore fistulados no rúmen, de mesmo grupo contemporâneo. Os animais foram manejados no período seco do ano como no 
experimento 1, com ingestão forçada das sobras dos suplementos via cânula para o consumo predito da mistura proteico-energética.

A área de pastagem foi composta por piquetes de capim braquiária (Brachiaria decumbens). As amostragens de forragem foram realizadas por meio de "gaiola de exclusão" $\left(1 \mathrm{~m}^{2}\right)$, adaptado do modelo proposto por Gardner (1986). Apresentou disponibilidade de forragem mínima de $3681,0 \mathrm{~kg}$ MS.ha $^{-1}$ no extrato de pastejo, com teor médio de $88,0 \%$ de MS.

Foi usado o DQL 3 x 3 (x2), onde cada animal foi sorteado aleatoriamente nos tratamentos e nos período, cujo modelo matemático é: $y_{i j k}=m$ $+\alpha_{i}+t_{i}+\beta_{k(i j)}+e_{i j k}$; onde: $y_{i j k}$ equivale ao valor observado na $j$-ésima unidade experimental, no $i$-ésimo período que recebeu o $k$-ésimo tratamento; $m$ significa a média geral; $\alpha_{i}$ equivale ao efeito do $i$-ésimo período (linha); $t_{i}$ equivale ao efeito da $j$-ésima unidade experimental (coluna); $\beta_{k}$ equivale ao efeito do $k$-ésimo tratamento; $e_{i j k}$ é o erro experimental associado a observação $y_{i j^{\prime}}$ Os dados coletados foram analisados estatisticamente com auxilio do programa Statistical Analysis System (SAS, 2000), com médias comparadas pelo teste de Tukey $(\mathrm{P}>0,05)$.

Foram avaliados o consumo médio diário, estimado através da diferença entre a quantidade fornecida e as sobras no cocho. Para determinação do $\mathrm{pH}$ utilizou-se pHmetro digital portátil (adaptado de CABRAL et al., 2008) e para determinação da concentração de nitrogênio amoniacal (mg N-NH3/ dL) a metodologia proposta por Chaney e Marbach (1962). As coletas de líquido ruminal feitas via fístula ruminal no tempo 0 (zero) imediatamente antes de ser oferecido o suplemento proteico-energético aos animais e os tempos 2, 4, 6 e 8 horas após o inicio da suplementação (MASSARO JUNIOR et al., 2013).

Para o ensaio de degradabilidade ruminal, foram utilizados sacos de nylon (poli-amida) de porosidade de 50 micras com área de contato de $225 \mathrm{~cm}^{2}$ (15 $\mathrm{x} 7,5 \mathrm{~cm}$, duas faces), os quais continham em seu interior feno de Brachiaria decumbens, coletada na mesma área de pastejo, e que foram incubados em 12 tempos, sendo 144, 120, 96, 72, 48, 24, 12, 8, 6, 4, 2 horas e tempo 0 (zero) ao retirar, adaptado da metodologia proposta por Casali et al. (2008).

Os parâmetros analisados foram ajustados de acordo com a equação proposta por Ørskov e McDonald (1979). A degradabilidade ruminal in situ da matéria seca (MS), da fibra em detergente neutro (FDN) e fibra em detergente ácido (FDA) foi calculada de acordo com a seguinte equação: $\mathrm{dg}=\mathrm{a}+\mathrm{b}\left(1-\mathrm{e}^{-\mathrm{ct}}\right)$, em que: $\mathrm{dg}=$ degradabilidade estimada; $a$ = fração rapidamente solúvel; $b=$ fração insolúvel, mas potencialmente degradável; $\mathrm{c}=$ taxa constante de degradação da fração b; e = logaritmo natural e; $\mathrm{a}+\mathrm{b}=$ potencial de degradabilidade; e $\mathrm{t}=$ tempo de incubação. Considerou-se a taxa de passagem dos alimentos pelo rúmen em animais em pastejo, como sugerido pelo AFRC (1994), sendo os valores de 2,5 e $8 \% /$ h para consumo menor, igual e maior do que a mantença, respectivamente.

Após analise de DISMS, procedeu-se a avaliação da DISFDN e da DISFDA pelo método sequencial (SILVA, 1990; BERCHIELLI et al., 2001). As análises foram processadas com auxilio do programa FitCurve6 para Windows ${ }^{\circledR}$ XP (HOVELL, 1995), para calculo de degradabilidade ruminal onde se avalia a degradação potencial; lag time (tempo de colonização microbiana); degradação das frações "a" (fração rapidamente solúvel), "b" (fração potencialmente degradável) e "c" (taxa constante de degradação); degradabilidade efetiva e degradabilidade solúvel em água.

\section{Resultados e Discussão}

Para os resultados obtidos no experimento 1, foi observado (Tabela 2) que não houve diferença entre os grupos experimentais para as variáveis analisadas. Verificou-se que houve redução no consumo de suplemento nos animais dos grupos experimentais em relação ao consumo predito de $300 \mathrm{~g} / \mathrm{animal} / \mathrm{dia}$. 
Tabela 2. Valores médios de consumo de suplemento e desempenho animal no período seco do ano (Experimento 1).

\begin{tabular}{|c|c|c|c|c|c|}
\hline \multirow{2}{*}{ Variáveis } & \multicolumn{3}{|c|}{ Tratamentos } & \multirow{2}{*}{ EP } & \multirow{2}{*}{$\mathbf{P}$} \\
\hline & Controle & VM 100 & VM 200 & & \\
\hline CSPE (g/animal/dia) & 208,2 & 186,0 & 185,9 & 1,94 & 0,8743 \\
\hline CAd (mg/animal/dia) & 0 & 67,0 & 133,8 & - & - \\
\hline PV inicial $(\mathrm{kg})$ & 294,4 & 302,9 & 285,7 & - & - \\
\hline PV final (kg) & 339,4 & 347,0 & 334,4 & 0,11 & 0,4478 \\
\hline CSPE / 100 kg PV (g/dia) & 61,3 & 53,6 & 55,6 & 1,94 & 0,8743 \\
\hline CAd/ 100 kg PV (mg/dia) & 0 & 19,3 & 40,0 & - & - \\
\hline GMD (kg/animal/dia) & 0,398 & 0,391 & 0,431 & 0,11 & 0,4478 \\
\hline
\end{tabular}

Controle $=$ Tratamento controle, apenas suplemento mineral comigo - produção - f.10 proteico-energético (SPE);

VM 100= Tratamento virginiamicina 100, SPE $+108 \mathrm{mg}$ de (phigrow $\left.{ }^{\circledR}\right)$ vm/animal/dia;

VM 200= Tratamento virginiamicina 200, SPE $+216 \mathrm{mg}$ de (phigrow $\left.{ }^{\circledR}\right) \mathrm{vm} / \mathrm{animal} / \mathrm{dia}$;

Médias na mesma linha não diferem entre si estatisticamente $(\mathrm{P}>0,05)$;

EP - erro padrão; P - valor P de comparação da variável entre os tratamentos; CSPE - consumo de suplemento proteico-energético;

CAd - consumo de aditivo; PV - peso vivo; GMD - ganho médio diário.

Fonte: Elaboração dos autores.

A inclusão de aditivos antimicrobianos já é consagrada para animais criados ou terminados em sistema de confinamento, onde recebem dietas com alta proporção de alimentos concentrados, para diminuir a incidência de distúrbios metabólicos e melhorar a eficiência alimentar como principais objetivos. Contudo, para animais criados em pastagens diferidas, as experimentações são escassas. As respostas em desempenho para bovinos em pastejo dependem de fatores ainda não totalmente caracterizados, sendo que vários fatores interferem na resposta à utilização de aditivos. Em se tratando de animais zebuínos em pastejo de gramíneas tropicais com distinção do período seco e o das águas, situação mais comum no Brasil, os estudos se tornam ainda mais escassos.

Alguns experimentos demonstram que a variação no consumo de suplemento utilizado para veicular o aditivo antimicrobiano a ser utilizado na dieta de bovinos em pastejo, depende mais do manejo nutricional alimentar do que do uso e da dose diária do aditivo (VELASCO et al., 1998).
Tem sido atribuido que o efeito primário da suplementação com aditivos antimicrobianos sobre o desempenho dos animais é melhor explicado por uma redução de 8 a $10 \%$ nos gastos energéticos relacionados à mantença. Em bovinos mantidos a pasto, a redução dos custos energéticos de mantença em $9 \%$ equivale a um incremento no ganho de peso de $84 \mathrm{~g} /$ animal/dia (SALINAS-CHAVIRA et al., 2009), ou de 90 a 140 gramas/animal/dia a mais quando comparado com suplementos sem utilização destas tecnologias (COAN; GRANDINI, 2010), resultados os quais para virginiamicina se encontra na faixa, 118g/animal/dia. Desta forma, os nutrientes disponibilizados via alimentos podem ser mais bem aproveitados e os nutrientes via suplementos tem o seu uso maximizado.

As medidas biométricas dos animais apresentaram diferenças apenas para comprimento corporal, que foram maoires nos animais do grupo controle e VM100. As demais medidas biométricas não apresentaram diferenças estatísticas entre os tratamentos (Tabela 3), o que gera a necessidade de buscar novas informações a respeito do uso da virginiamicina nesse sentido. 
Tabela 3. Valores médios das medidas biométricas dos animais no período seco.

\begin{tabular}{|c|c|c|c|c|c|}
\hline \multirow{2}{*}{ Variáveis } & \multicolumn{3}{|c|}{ Tratamentos } & \multirow{2}{*}{ EP } & \multirow{2}{*}{$\mathbf{P}$} \\
\hline & Controle & VM 100 & VM 200 & & \\
\hline Escore de Condição Corporal & 4,5 & 4,4 & 4,5 & 0,31 & 0,3880 \\
\hline Compr. Corporal (cm) & $116,5^{b}$ & $115,4^{b}$ & $112,6^{\mathrm{a}}$ & 47,5 & 0,0033 \\
\hline Altura de Cernelha (cm) & 134,6 & 133,6 & 133,3 & 55,6 & 0,4055 \\
\hline Altura de Garupa (cm) & 143,3 & 141,1 & 141,3 & 16,9 & 0,0912 \\
\hline Perímetro Torácico (cm) & 166,5 & 166,4 & 164,4 & 16,5 & 0,4025 \\
\hline Largura de Garupa (cm) & 44,9 & 45,5 & 44,1 & 29,3 & 0,1360 \\
\hline Largura de Peito $(\mathrm{cm})$ & 37,4 & 37,3 & 37,5 & 10,0 & 0,6411 \\
\hline
\end{tabular}

Controle $=$ Tratamento controle, apenas suplemento mineral comigo - produção $-\mathrm{f} .10$ proteico-energético (SPE);

VM 100= Tratamento virginiamicina 100, SPE $+108 \mathrm{mg}$ de (phigrow $\left.{ }^{\circledR}\right)$ vm/animal $/$ dia;

VM 200= Tratamento virginiamicina $200, \mathrm{SPE}+216 \mathrm{mg}$ de (phigrow $\left.{ }^{\circledR}\right) \mathrm{vm} / \mathrm{animal} / \mathrm{dia}$;

Médias seguidas de mesma letra na mesma linha não diferem entre si estatisticamente $(\mathrm{P}>0,05)$;

EP - erro padrão; P - valor P de comparação da variável entre os tratamentos.

Fonte: Elaboração dos autores.

De acordo com Di Marco, Barcellos e Costa (2007) vários fatores podem interferir na composição química (proteína, extrato etéreo, água e matéria mineral), na proporção e no local de deposição dos tecidos muscular e ósseo e na proporção e no local de deposição do tecido adiposo (subcutânea, intermuscular, mesentérica e perírrenal), assim como dos componentes não carcaça. Alguns destes importantes fatores estão relacionados com as ações nutricionais agindo no metabolismo animal.

$\mathrm{O}$ entendimento das mudanças que os aditivos promovem no metabolismo ruminal passa a ter um papel muito importante. Assim, é discutido os resultados obtidos no Experimento 2, onde não houve diferença significativa $(\mathrm{P}>0,05)$ do consumo de suplemento proteico-energético (Tabela 4). Em todos os tratamentos, o consumo de suplemento proteico-energético foi reduzido de 39,8 a $56,0 \%$ em relação ao consumo predito de $300 \mathrm{~g} /$ animal/ dia, sendo o efeito mais acentuado nos animais do grupo VM 200.

Aditivos antimicrobianos usados em suplementos de baixo consumo tende a promover menor consumo diário, maior variabilidade de consumo por animal e por animal por dia no decorrer do período de uso (COCKWILL et al., 2000). Contudo, nem sempre a virginiamicina provoca redução do consumo de suplemento, por ser mais palatável ou ter maior aceitabilidade, podendo ate mesmo estimular o consumo (COAN; GRANDINI, 2010).

Os resultados observados indicam que essa redução do consumo pode ter sido influenciada em função do manejo dos animais, os quais já haviam sido submetidos a intervenção cirúrgica para canulação e no período experimental por constantes manipulações da cânula ruminal e movimentações na área experimental. $\mathrm{O}$ estresse do manejo foi uma das causas de redução de consumo do suplemento proteico-energético para animais criados em sistema de pastejo nesta experimentação. 
Tabela 4. Valores médios de consumo de suplemento proteico-energético (CSPE) no período seco (Experimento 2).

\begin{tabular}{|c|c|c|c|c|c|}
\hline \multirow{2}{*}{ Variáveis } & \multicolumn{3}{|c|}{ Tratamentos } & \multirow{2}{*}{ EP } & \multirow{2}{*}{$\mathbf{P}$} \\
\hline & Controle & VM 100 & VM 200 & & \\
\hline CSPE (g/ animal/ dia) & $180,5^{\mathrm{a}}$ & $180,3^{\mathrm{a}}$ & $132,0^{\mathrm{b}}$ & 93,8 & 0,0491 \\
\hline CAd (mg/ animal/ dia) & 0 & 64,91 & 95,04 & - & - \\
\hline CSPE forçado (g/ animal/ dia) & 119,5 & 119,7 & 168,0 & - & - \\
\hline CAd forçado (mg/ animal/ dia) & 0 & 43,09 & 120,96 & - & - \\
\hline CAd total (mg/ animal/ dia) & 0 & 108 & 216 & - & - \\
\hline
\end{tabular}

Controle $=$ Tratamento controle, apenas suplemento mineral comigo - produção - $\mathrm{f} .10$ proteico-energético (SPE);

VM $100=$ Tratamento virginiamicina 100, SPE $+108 \mathrm{mg}$ de (phigrow $\left.{ }^{\circledR}\right)$ vm/animal $/$ dia;

VM $200=$ Tratamento virginiamicina 200, SPE $+216 \mathrm{mg}$ de (phigrow $\mathbb{R})$ vm/animal $/$ dia;

Médias seguidas de mesma letra na mesma linha não diferem entre si estatisticamente $(\mathrm{P}>0,05)$;

EP - erro padrão; P - valor P de comparação da variável entre os tratamentos; CSPE - consumo de suplemento proteico-energético; CAd - consumo de aditivo.

Fonte: Elaboração dos autores.

Mesmo com o consumo predito do suplemento proteico-energético sendo atendido pela ingestão forçada, não houve diferença significativa $(\mathrm{P}>0,05)$ nos valores médio do $\mathrm{pH}$ ruminal nos animais de todos os tratamentos, sendo os valores de 7,02 para os animais do tratamento controle, 7,04 para VM 100 e 7,06 para VM 200. Todos os animais dos diferentes tratamentos apresentaram uma faixa ótima de $\mathrm{pH}$ ruminal de 6,2 a 7,1, valores estes recomendados para o bom funcionamento do rúmen, sem que possa causar algum distúrbio.

Vários fatores podem afetar a população microbiana do rúmen, dentre estes o uso de aditivos antimicrobianos e o pH ruminal, assim desencadeando eventos nutricionais, fisiológicos e metabólicos que agem na taxa de digestão dos alimentos consumidos.

Aredução do pH no rúmen leva a efeitos adversos, que incluem redução na digestão da fibra, redução na motilidade ruminal, inapetência, aumento de histamina e das concentrações de endotoxinas, acidose, rumenitis sistêmica, laminite, abscessos de fígado e morte (PAGE, 2003). O decréscimo do $\mathrm{pH}$ ruminal promove a depressão na digestão da proteína, celulose, hemicelulose e pectina, com menor efeito sobre a digestão do amido (HOOVER;
STOKES, 1991). Em situações de $\mathrm{pH}$ ruminal inferior a 6,2, ocorre redução na digestão da fibra, devido à sensibilidade das bactérias fibrolíticas, e o ponto mais favorável da digestão da fibra acontece quando os valores de $\mathrm{pH}$ ruminal estão entre 6,7 e 7,1 (PAGE, 2003).

Assim como o $\mathrm{pH}$ ruminal, outra variável que deve-se analisar é a concentração de nitrogênio amoniacal no rúmen, pois este pode comprometer a atividade dos microrganismos ruminais, em especial aqueles que degradam carboidratos fibrosos que é dependente do nível de nitrogênio amoniacal no rúmen, assim, pode-se verificar se a dieta fornecida está adequada às características fisiológicas do ruminante. $\mathrm{O}$ uso de aditivos seletores da microbiota ruminal tem o objetivo de promover níveis de nitrogênio amoniacal adequados ao crescimento microbiano.

É demonstrado na Figura 1 a variação da concentração de nitrogênio amoniacal (em mg $\mathrm{N}-\mathrm{NH} 3 / \mathrm{dL}$ ) no período seco no decorrer do tempo após a suplementação, as quais não apresentaram diferenças estatísticas significativas $(\mathrm{P}<0,05)$ entre os tratamentos, sendo 3,961, 3,876 e 4,147 mg $\mathrm{N}-\mathrm{NH} 3 / \mathrm{dL}$ para animais dos tratamentos controle, VM 100 e VM 200 respectivamente. 
Figura 1. Valores médios da concentração de Nitrogênio Amoniacal (em mg N-NH3/dL) no decorrer do tempo após a suplementação, no período seco.

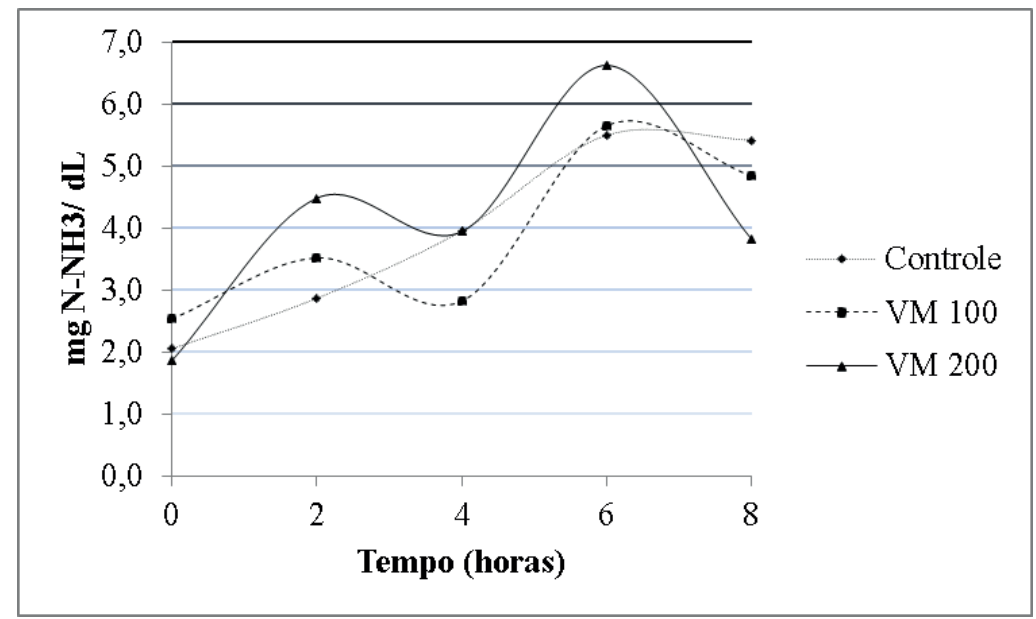

Controle $=$ Tratamento controle, apenas suplemento mineral comigo - produção - f.10 proteico-energético (SPE);

VM $100=$ Tratamento virginiamicina $100, \mathrm{SPE}+108 \mathrm{mg}$ de (phigrow ${ }^{\circledR}$ ) vm/animal/dia;

VM 200= Tratamento virginiamicina 200, SPE + $216 \mathrm{mg}$ de (phigrow ${ }^{\circledR}$ ) vm/animal/dia.

Fonte: Elaboração dos autores.

Manter constante a adequada concentração de nitrogênio amoniacal no rúmen é, portanto, indispensável para o crescimento bacteriano. É relatado por Stern e Hoover (1979) que nas mais variadas situações, 40 a $100 \%$ do nitrogênio exigido pelos microrganismos poderia ser derivado do nitrogênio amoniacal. A concentração mínima necessária para manter máxima taxa de crescimento microbiano varia de acordo com a fermentação da dieta. Alem disso, existe um sinergismo entre os níveis de acidez $(\mathrm{pH})$ e de nitrogênio amoniacal no rúmen; por meio deles, é possível aumentar o crescimento microbiano e a degradação da fibra do alimento, obtendo-se assim maior consumo de alimentos.

Os resultados obtidos apresentam valores adequados para maximização da digestão ruminal da matéria seca em condições tropicais, onde são necessárias concentrações que variam de 3,3 a 8,0 mg N-NH3/dL para que ocorra a maximização do consumo (HOOVER, 1986), os quais corroboram com os valores encontrados nesta pesquisa.
A concentração de nitrogênio amoniacal no rúmen é conseqüência do equilíbrio entre sua produção, absorção e utilização pelos microrganismos. Bactérias ruminais utilizam nitrogênio amoniacal como fonte de nitrogênio para a síntese de proteína microbiana, mas a fermentação ruminal da proteína produz mais N-NH3 ruminal que os microrganismos podem utilizar (PRESTON, 1986).

Além do $\mathrm{pH}$ ruminal e a concentração de nitrogênio amonical, outros fatores influenciam a digestão ruminal e a absorção de nutrientes. Dentre estes está a degradabilidade do conteúdo ingerido, que em se tratando de animais em pastejo ou recebendo dietas com alta porção de volumosos merece destaque a degradabilidade da matéria seca e das fibras.

A Tabela 5 apresenta os resultados de degradabilidade da matéria seca, que para as condições desta pesquisa não apresentou diferença significativa $(\mathrm{P}>0,05)$ para nenhuma das variáveis analisadas. 
Tabela 5. Valores médios de degradabilidade in situ da matéria seca (DISMS) no período seco.

\begin{tabular}{|c|c|c|c|c|c|}
\hline \multirow{2}{*}{ Variáveis } & \multicolumn{3}{|c|}{ Tratamentos } & \multirow{2}{*}{ EP } & \multirow{2}{*}{$\mathbf{P}$} \\
\hline & Controle & VM 100 & VM 200 & & \\
\hline Degradação Potencial (\%) & 64,7 & 77,8 & 69,6 & 52,1 & 0,2502 \\
\hline Lag Time (h) & 5,87 & 8,25 & 6,13 & 20,5 & 0,3614 \\
\hline \multicolumn{6}{|c|}{ Parâmetros Ajustados } \\
\hline Fração "a" & 16,5 & 16,9 & 17,5 & 3,05 & 0,5491 \\
\hline Fração "b" & 48,3 & 77,3 & 52,2 & 29,7 & 0,2002 \\
\hline Fração "c" & 0,023 & 0,015 & 0,018 & 0,00 & 0,1636 \\
\hline \multicolumn{6}{|c|}{ Degradabilidade Efetiva } \\
\hline $2 \% /$ hora & 41,8 & 39,7 & 41,8 & 17,4 & 0,2092 \\
\hline $5 \% /$ hora & 31,9 & 29,8 & 31,9 & 17,5 & 0,1370 \\
\hline $8 \%$ / hora & 28,1 & 26,6 & 28,3 & 10,8 & 0,1651 \\
\hline
\end{tabular}

Controle $=$ Tratamento controle, apenas suplemento mineral comigo - produção $-\mathrm{f} .10$ proteico-energético (SPE);

VM 100= Tratamento virginiamicina 100, SPE $+108 \mathrm{mg}$ de (phigrow $\left.{ }^{\circledR}\right)$ vm/animal/dia;

VM 200= Tratamento virginiamicina 200, SPE $+216 \mathrm{mg}$ de (phigrow $\left.{ }^{\circledR}\right) \mathrm{vm} / \mathrm{animal} / \mathrm{dia}$;

Médias seguidas de mesma letra na mesma linha não diferem entre si estatisticamente $(\mathrm{P}>0,05)$;

EP - erro padrão; P - valor P de comparação da variável entre os tratamentos.

Fonte: Elaboração dos autores.

As gramíneas tropicais apresentam limitações quanto ao aspecto qualitativo com reduzido conteúdo celular e grande deposição de conteúdo na parede celular. A fração fibrosa, em geral apresenta lenta e incompleta digestão, sendo a principal responsável pela variação na digestão dos alimentos. Este alto teor de fibras apresentado pelo material incubado nesta pesquisa aumenta a dificuldade de detecção de diferenças estatísticas quando utilizamos aditivos seletores da microbiota ruminal.

A manipulação da microbiota ruminal com uso de aditivos antimicrobianos ou seletores da microbiota, terá pouco efeito sobre a degradabilidade do conteúdo ingerido quando este apresenta partículas de tamanhos consideráveis, como demonstrado neste trabalho, onde os animais tiveram pastagem tropical diferida sem nenhum processamento como dieta base.

Foi avaliado a degradabilidade ruminal in situ da fibra em detergente neutro, que não houve diferenças estatísticas $(\mathrm{P}>0,05)$ para nenhum dos parâmetros analisados no período seco.

A degradabilidade do alimento é a sua capacidade de permitir que o animal utilize, em maior ou menor escala, seus nutrientes. Essa capacidade é expressa pelo coeficiente de degradabilidade dos componentes nutricionais de interesse. A degradabilidade e o consumo são dois dos principais componentes que determinam o valor nutritivo de um alimento. De todos os nutrientes necessários às exigências nutricionais para mantença, crescimento e/ou produção dos bovinos, a energia oriunda da degradação ruminal de celulose, hemicelulose e lignina, principais constituintes da fibra em detergente neutro, constitui a principal contribuição dos volumosos e que de acordo Van Soest (1994), o teor de FDN do alimento é inversamente relacionado com o consumo voluntário de alimentos.

Em situação similar aos apresentados nesta pesquisa, Goulart (2010) demonstrou que com a virginiamicina não se observou alteração em ganho de peso, mas houve melhoria da eficiência de conversão alimentar. Apesar de não ter encontrado diferenças significativas na degradabilidade ruminal e pós-ruminal da matéria orgânica, fibra em detergente neutro (FDN) e nitrogênio não foram afetadas pela virginiamicina. Desta forma, 
os nutrientes disponibilizados via alimentos podem ser mais bem aproveitados e os nutrientes via suplementos tem o seu uso potencializados.

A degradabilidade ruminal in situ da fibra em detergente ácido não apresentou diferenças estatísticas $(\mathrm{P}>0,05)$.

A fibra em detergente ácido é a porção de menor degradabilidade da parede celular. É constituída de lignocelulose (lignina e celulose), sendo inversamente proporcional à digestibilidade, pois quanto mais alta a percentagem de fibra em detergente ácida, mais baixa é a digestibilidade do material (VAN SOEST, 1994).

A contribuição dos aditivos seletores da microbiota ruminal sobre a digestibilidade da fibra é que eles podem diminuir a concentração de lactato no rúmen, desta forma, a redução do $\mathrm{pH}$ nesse ambiente será limitado, propiciando assim, melhores condições para o desenvolvimento de bactérias celulolíticas. Mas esses efeitos não seriam perceptíveis em situações onde a dieta contem altas proporções de alimentos volumosos ou quase que exclusivo de volumosos, como neste estudo, devido aos efeitos do alto teor de fibra.

O acréscimo em eficiência de crescimento causado pelo uso de aditivos seletores da microbiota ruminal às vezes pode ser explicado em parte pelo aumento na degradabilidade dos constituintes alimentares, em especial a matéria seca e as fibras em se tratando de gramíneas tropicais. Contudo, é necessário que outras variáveis sejam avaliadas de forma simultânea, já que é possível trazer outros benefícios com o uso de aditivos antimicrobianos sem que haja mudanças em alguns parâmetros.

\section{Conclusões}

A inclusão de virginiamicina promoveu acentuada redução no consumo do suplemento em bovinos sob pastejo diferido e não influenciou os valores do $\mathrm{pH}$ ruminal, nas concentrações de nitrogênio amoniacal no rúmen, na degradabilidade da matéria seca e das fibras em detergente neutro ou ácido.

Alguns efeitos que a virginiamicina pode promover, ainda não estão muito bem esclarecidos. Portanto, são necessárias pesquisas adicionais que levem à compreensão das particularidades da molécula de virginiamicina.

\section{Agradecimentos}

Ao Programa de Pós-Graduação em Ciência Animal (DPA/EVZ-UFG), ao Centro Tecnológico COMIGO (CTC - COMIGO) e à PHIBRO Saúde Animal Internacional LTDA.

\section{Referências}

AGRICULTURALEND FOOD RESEARCH COUNCIL - AFRC. The nutrient requirements of ruminant livestock. Famham Royal: CAB International, 1994. 351 p.

BERCHIELLI, T. T.; SADER, A. P. O.; TONANI, F. L.; PAZIANI, S. D. F.; ANDRADE, P. D. Avaliação da determinação da fibra em detergente neutro e da fibra em detergente ácido pelo sistema ANKOM. Revista Brasileira de Zootecnia, Viçosa, MG, v. 30, n. 5, p. 15721578, 2001.

CABRAL, L. S.; VALADARES FILHO, S. C.; DETMANN, E.; ZERVOUDAKIS, J. T.; SOUZA, A. L.; VELOSO, R. G. Eficiência microbiana e parâmetros ruminais em bovinos alimentados com dietas à base de volumosos tropicais. Revista Brasileira de Zootecnia, Viçosa, MG, v. 37, n. 5, p. 919-925, 2008.

CASALI, A. O.; DETMANN, E.; VALADARES FILHO, S. D. C.; PEREIRA, J. C.; HENRIQUES, L. T.; FREITAS, S. G. D.; PAULINO, M. F. Influência do tempo de incubação e tamanho de partículas sobre os teores de compostos indigestíveis em alimentos e fezes bovinas obtidos por procedimento in situ. Revista Brasileira de Zootecnia, Viçosa, MG, v. 37, n. 2, p. 335-342, 2008.

CHANEY, A. L.; MARBACH, E. P. Modified reagents for determination of urea and ammonia. Clinical Chemistry, Washington, v. 8, n. 2, p. 130-132, 1962.

COAN, R. M.; GRANDINI, D. Maximizando os resultados da suplementação mineral nas águas. Parte 1. Jaboticabal; Coan Consultoria, 2010. Disponivel em: $<$ http://www.coanconsultoria.com.br/especialistas. asp?id=28>. Acesso em: 7 fev 2012. 
COCKWILL, C. L.; MCALLISTER, T. A.; OLSON, M. E.; MILligAN, D. N.; RALSTON, B. J.; HUISMA, C.; HAND, R. K. Individual intake of mineral molasses supplements by cows, heifers and calves. Canadian Journal of Animal Science, Ottawa, v. 80, n. 4, p. 681690, 2000.

DI MARCO, O. N.; BARCELlOS, J. O. J.; COSTA, E. C. Crescimento de bovinos de corte. Porto Alegre: Universidade Federal do Rio Grande do Sul, 2007. 276 p.

FRENEAU, G. E.; SILVA, J. C. C.; BORJAS, A. L. R.; AMORIM, C. Estudo de medidas corporais, peso vivo e condição corporal de fêmeas da raça Nelore (Bos taurus indicus) ao longo de 12 meses. Ciência Animal Brasileira, Goiânia, v. 9, n. 1, p. 76-85, 2008.

GARDNER, A. L. Técnicas de pesquisa em pastagens e aplicabilidade de resultados em sistemas de produção. Brasília: II CA/EMBRAPA-CNPGL, 1986. 197 p. (Série Publicações Miscelâneas, 634).

GOULART, R. C. D. Avaliação de antimicrobianos como promotores de crescimento via mistura mineral para bovinos de corte em pastejo. 2010. Tese (Doutorado em Ciência Animal e Pastagens) - Universidade de São Paulo, Piracicaba.

HOVELL, F. D. B. Measurement of roughage or protein degradation using the polyester bag "in sacco" technique. Fit curve user manual. 1995. Disponível em: $<$ http://www.macaulay.ac.uk/IFRU/software>. Acesso em: 22 abr. 2010.

HOOVER, W. H.; STOKES, S. R. Balancing carbohydrates and proteins for optimum rumen microbial yield. Journal of Dairy Science, Champaign, v. 74, n. 10, p. 3630-3644, 1991.

HOOVER, W. H. Chemical factors involved in ruminal fiber digestion. Journal of Dairy Science, Champaign, v. 69, n. 10, p. 2755-2766, 1986.

MALAFAIA, P.; CABRAL, L. S.; VIEIRA, R. A. M.; COSTA, R. M.; CARVALHO, C. A. B.; Suplementação protéico-energética para bovinos criados em pastagens: Aspectos teóricos e principais resultados publicados no Brasil. Livestock Research for Rural Development, Cali, v. 15, n. 12, artigo 6, 2003.

MASSARO JUNIOR, F. L.; SILVA, L. D. D. F.; FORTALEZA, A. P. S.; BERAN, F. H. B.; CASTRO, V. S.; RIBEIRO, E. L. A.; BARBOSA, M. A. A. F.; BUMBIERIS JUNIOR, V. H.; MIZUBUTI, I. Y.; PRADO, O. P. P. Comportamento ingestivo e metabólico de bovinos alimentados com ração contendo probióticos. Semina: Ciências Agrárias, Londrina, v. 34, n. 6, p. 4157-4166, 2013. Suplemento 2.
ØRSKOV, E. R.; McDONALD, I. The estimation of protein degradability in the rumen from incubation measurements weighted according to rate of passage. Journal of Agricultural Science, New York, v. 92, n. 1, p. 499-503, 1979.

PAGE, S. W. The role of enteric antibiotics in livestock production. A review of published literature. Canberra: Avcare Ltd, 2003. 450p.

PRESTON, T. R. Analytical methods for characterizing. In: FAO Corporate Document Repositori. Feed resources for ruminants. Better utilization of crop residues and by products in animal feeding: research guidelines. 2 . A practical manual for research workers. Rome: FAO, 1986. $106 \mathrm{p}$.

ROGERS, J. A.; BRANINE, M. E.; MILLER, C. R.; WRAY, M. I.; BARTLE, S. J.; PRESTON, R. L.; GILL, D. R.; PRITCHARD, R. H.; STILBORN, R. P.; BECHTOL, D. T. Effects of dietary virginiamycin on performance and liver abscess incidence in feedlot cattle. Journal of Animal Science, Champaign, v. 73, n. 1, p. 9-20, 1995.

SALINAS-CHAVIRA, J.; LENIN, J.; PONCE, E.; SANCHEZ, U.; TORRENTERA, N.; ZINN, R. A. Comparative effects of virginiamycin supplementation on characteristics of growth-performance, dietary energetics, and digestion of calf-fed Holstein steers. Journal of Animal Science, Champaign, v. 87, n. 12, p. 4101-4108, 2009.

STATISTICAL ANALYSIS SYSTEM - SAS. SAS/ STAT. User's guide: statistics, versão 8.1. $4^{\text {th }}$ ed. v. 2, Cary: SAS Institute, 2000. CD-ROM.

SILVA, D. J. Análise de alimentos: métodos químicos e biológicos. Viçosa: UFV, 1990. 166 p.

SPITZER, J. C. Influences of nutrition on reproduction in beef cattle. In: MORROW, D. A. (Ed.). Current therapy in theriogenology. $2^{\text {th }}$ ed. Philadelphia: W. B. Saunders, 1986. p. 231-234.

STERN, M. D.; HOOVER, W. H. Methods for determining and factors affecting rumen microbial protein syntheses: a review. Journal of Animal Science, Champaign, v. 49, n. 5, p. 1590-1603, 1979.

VAN SOEST, P. J. Nutritional ecology of the ruminant. $2^{\text {th }}$ ed. Ithaca: Cornell University Press. 1994. 476 p.

VELASCO, R. R.; MARTÍNEZ, G. D. M.; GALVÁN, M. M. C.; CABRENA, E. S. Manejo nutricional en corrales de engorda. Veterinaria México, v. 29, n. 3, p. 291-297, 1998. 
